\title{
ESTUDO DA VARIAÇÃO MORFO-SEDIMENTAR DOS CANAIS DE DESPESCA DE UMA FAZENDA DE CULTIVO DE CAMARÃO E SUAS IMPLICAÇÕES AMBIENTAIS
}

\author{
Danilo L. M. Ferraz ${ }^{1}$, Leão Xavier da Costa Neto ${ }^{2}$ \\ ${ }^{1}$ Graduando em Tecnologia em Meio Ambiente - CEFET-RN; \\ guardian_ferraz@yahoo.com.br \\ ${ }^{2}$ Professor do CEFET-RN, Mestre em Geologia e Geofísica Marinha pela UFF-RJ; \\ leaoneto@eol.com.br
}

Recebido em outubro de 2004 e Aceito em abril de 2005

\begin{abstract}
RESUMO
Este estudo é produto do projeto apresentado a Diretoria de Pesquisa do Centro Federal de Educação Tecnológica do Rio Grande do Norte (CEFET/RN) em seu Programa Institucional de Iniciação Científica, bem como é parte do Plano de Monitoramento Ambiental proposto no EIA-RIMA da empresa de carcinicultura Camarus Aquacultura do Nordeste Ltda, localizada no município de Galinhos, litoral setentrional do RN, que prevê o monitoramento dos seus dois canais de despesca (CD 1 e 2) por um período de 2 anos, se estendendo até maio de 2006. Este trabalho se refere a 5 meses de monitoramento - maio a outubro de 2004. O CD 1 e 2 apresentam extensões de 2.500 e $1.000 \mathrm{~m}$, respectivamente; largura média de $10 \mathrm{~m}$ e uma profundidade média de $2,5 \mathrm{~m}$. A metodologia de trabalho consta de levantamento planialtimétrico mensal dos canais através de 6 perfis transversais com Estação Total, determinação semi-quantitativa das áreas de erosão e/ou sedimentação, coleta de água, análise de sólidos suspensos (SS) e caracterização textural dos sedimentos. O CD 1 mostra pontos de erosão e/ou deposição caracterizados como não significativos. No CD 2 não há evidência de erosão/deposição, mantendo um equilíbrio morfológico. Portanto, os perfis não mostram variações morfológicas significativas em escala temporal de pequena amplitude, ou seja, mensal, bimestral ou semestral. A maior concentração de SS na água ocorre em direção a montante uma vez que as correntes de marés apresentam menores velocidades. Nos perfis próximos a foz os SS apresentam menores concentrações. Os sedimentos do centro dos canais em perfis próximo a foz são areias e cascalhos, enquanto em direção a montante ocorrem lamas. Nas suas margem predominam lamas arenosas. A variação morfo-sedimentar dos CDs está associada aos seguintes fatores: configuração geométrica irregular com curvas em ângulos acentuados, penetração das fortes correntes de marés, atividade de despesca e precipitação pluviométrica.
\end{abstract}

Palavras-chave: carcinicultura, canais de despesca, erosão, sedimentação e meio ambiente.

\section{STUDY OF THE MORPHO-SEDIMENTAR VARIATION OF THE SHRIMP FARM'S DISCHARGE CHANNELS AND THEIR ENVIRONMENTAL IMPLICATIONS}

\begin{abstract}
This study is a product of the project presented to the Research Department of the Federal Center of Technological Education of Rio Grande do Norte, been a part of the
\end{abstract}


environmental monitoring plan proposed by the Environment Impact Study (EIA -RIMA) for the shrimp farm Camarus Aquacultura do Nordeste Ltda, located on Galinhos city, north coast of Rio Grande do Norte, that established the monitoring of their two discharge channels (CD 1 and 2) for a period of 2 years, until May 2006. This work refer to 5 months of monitoring - from May to October of 2004. The CD 1 and 2 have 2,500 and 1,000 m of length, respectively; $10 \mathrm{~m}$ of medium width and $2.5 \mathrm{~m}$ of medium depth. The work's methodology had monthly surveys of canals forms through 6 transversals profiles by using a Total Station, semi-quantity determination of erosion/sedimentation areas, water collection for Suspend Solids (SS) analysis, and sediments textural characterization. Erosion and/or sedimentation found in CD 1 were characterized as no-significant. The CD 2 did not present erosion/sedimentation evidences, maintaining a morphologic balance. Therefore, the profiles didn't show significant morphologic variations in a small temporal scale, such as by month, by two months or by a semester. The higher SS concentrations in water were determined in the upstream direction probably due to the slower speeds of tides. On the other hand SS concentrations decreased in downstream direction. Center sediments were characterized by the presence of sand and gravel in the most downstream points while in most upstream direction they were characterized by muds. In the banks predominated sandy muds. The CD's morpho-sedimentar variation is associated with following factors: irregular geometry configuration, having curves with accentuated angles; strong tides flows penetration; discharge activities for shrimp harvesting and pluviometry precipitations.

Key words: discharge channels, environment, erosion, sedimentation, shrimp farm. 


\section{ESTUDO DA VARIAÇÃO MORFO-SEDIMENTAR DOS CANAIS DE DESPESCA DE UMA FAZENDA DE CULTIVO DE CAMARÃO E SUAS IMPLICAÇÕES AMBIENTAIS}

\section{INTRODUÇÃO}

O presente trabalho foi elaborado a partir de pesquisa de campo realizada entre os meses de maio e outubro de 2004, como produto do projeto de pesquisa apresentado a Diretoria de Pesquisa do Centro Federal de Educação Tecnológica do Rio Grande do Norte (CEFET/RN), para o seu Programa Institucional de Iniciação Científica, fazendo também este, parte do plano de monitoramento ambiental proposto pelo Estudo de Impacto Ambiental (EIA-RIMA) da empresa de carcinicultura Camarus Aquacultura do Nordeste Ltda. Este projeto prevê o monitoramento dos canais de despesca por um período de 2 anos, se estendendo até maio de 2006.

O Rio Grande do Norte vem desde muito tempo sendo palco de atividades econômicas como as indústrias petrolífera e salineira, além da carcinicultura que nos últimos anos tem tido um grande crescimento, tornando o Estado o maior produtor de camarão em cativeiro do Brasil. Essas indústrias são responsáveis pela ocorrência de inúmeros impactos ambientais adversos decorrentes das suas diferentes atividades.

A carcinicultura é tida como uma atividade de grande potencial impactante ao meio ambiente, principalmente na sua fase de instalação, quando se faz necessário, na maioria das vezes, a realização de desmatamento de grandes áreas onde existe mangue para construção de seus viveiros e na fase de operação, devido ao descarte de efluentes não tratados e ao incremente de processos de erosão/deposição nos canais de despesca (CDs) e nos corpos hídricos.

Portanto, este trabalho tem o objetivo geral de estudar as alterações que ocorrem nos CDs da fazenda de cultivo de camarão da Camarus Aquacultura do Nordeste Ltda., bem como suas conseqüências no meio natural.

\section{LOCALIZAÇÃO E CARACTERIZAÇÃO DA ÁREA}

A fazenda de cultivo de camarão da Camarus Aquacultura do Nordeste Ltda, está localizada no município de Galinhos, litoral norte do estado do Rio Grande do Norte (Figura 01), no complexo estuarino-lagunar de Galinhos-Guamaré, mais especificamente na região denominada ilha do Pisa Sal (804099 m E e 9430557 m N), que tem como limite norte o Rio Galinhos, a sul a lagoa da Catanduba, a leste a estrada para o porto do Pratagil e a oeste o rio Pisa Sal. 


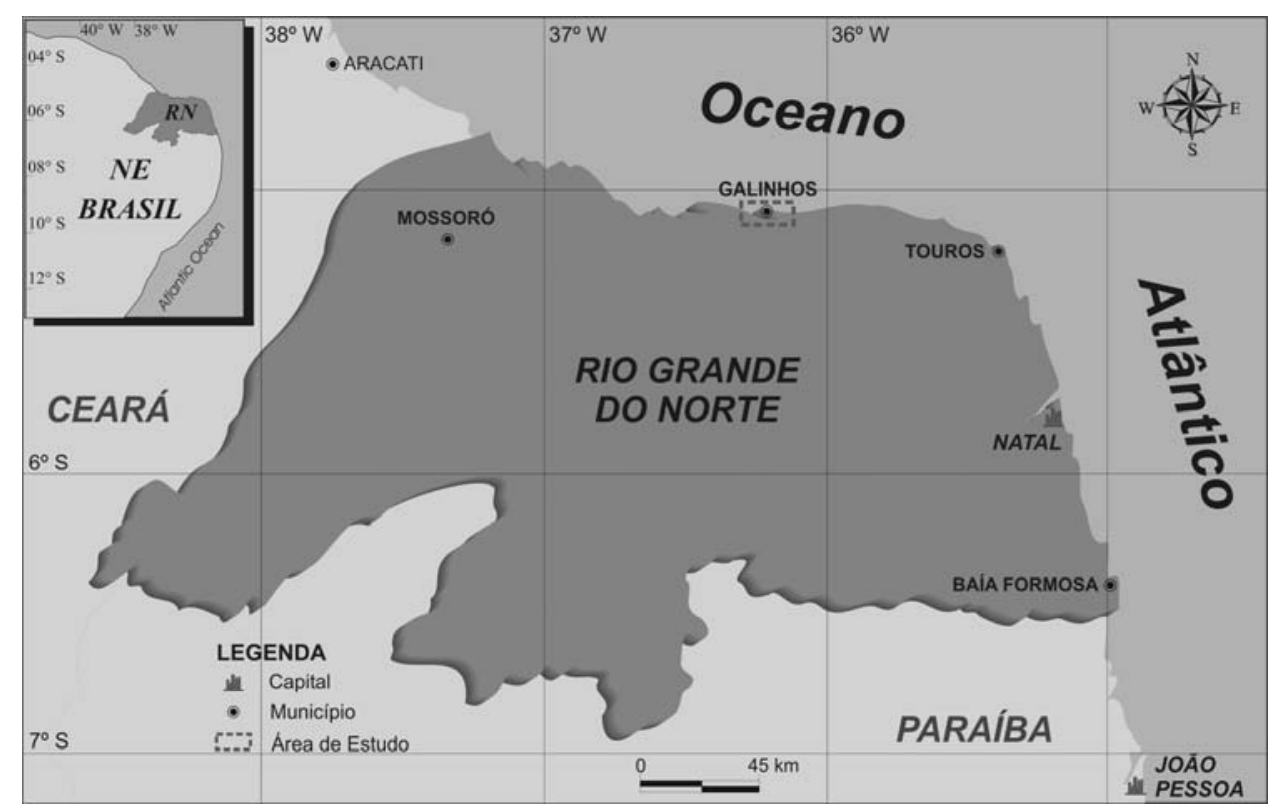

Figura 01- Localização da área, município de Galinhos/RN.

A fazenda de cultivo de camarão está em funcionamento desde o ano 2000, situando-se na margem direita do rio Pisa Sal, sendo constituída por 12 viveiros em operação, 1 central de bombeamento (bombagem), 1 canal de abastecimento e 2 CDs que fazem a drenagem da água dos viveiros durante despesca, os quais são objetos do presente estudo. Os CDs 1 e 2 apresentam extensões de 2.500 e $1.000 \mathrm{~m}$, respectivamente; largura de $10 \mathrm{~m}$ e uma profundidade média de 2,5m (Camarus Aquacultura do Nordeste Ltda, 2003).

Durante as fases de instalação e operação do projeto não ocorreu supressão da cobertura vegetal de mangue na planície de intermaré, zona sob influencia das marés de enchente e vazante. Entretanto, a planície de supramaré, área somente inundada nas marés altas de sizígia, onde não existia vegetação de mangue, foi fortemente modificada pela construção dos viveiros.

Os limites dos viveiros acompanhando a franja de mangue lhes conferindo uma geometria irregular e contribuindo para que os CDs fossem construídos apresentando curvas em fortes ângulos (Figura 02), incrementou os processo de erosão e sedimentação no interior dos mesmos, os quais foram detectados durante a elaboração do seu EIA-RIMA (Camarus Aquacultura do Nordeste Ltda, 2003). 


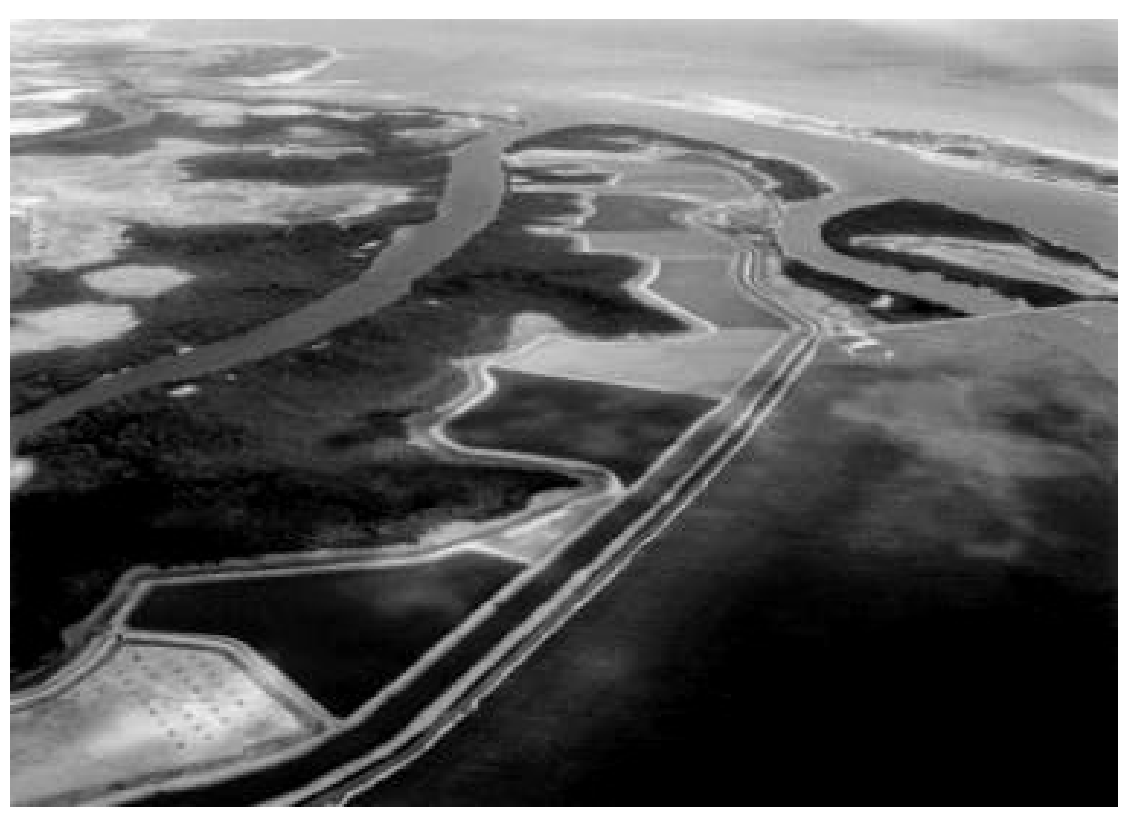

Figura 02- Viveiros e canal de despesca (CD 1) com configuração irregular.

A área de intervenção do empreendimento é constituída por sedimentos estuarinos subrecentes de composição arenosa (terraços estuarinos) e recentes de composição lamosa a areno lamosa (zonas de infra, inter e supramaré), onde ocorrem os ambientes de manguezal, apicun e planície de maré (Costa Neto et al., 2004).

As correntes de marés no interior dos CDs apresentam valores médios elevados (Tabela I), sendo um importante agente de transporte de sedimento nos CDs. As correntes de marés de vazante apresentam velocidades maiores que as de enchente, determinadas principalmente entre 1 h após a preamar (Costa Neto et al., 2003).

Tabela I- Velocidades das correntes de marés no interior dos CDs durante o período de enchente e vazante.

\begin{tabular}{c|c|c|c|c|c|c}
\hline \multirow{2}{*}{ CD } & \multicolumn{3}{|c|}{ Maré de Enchente (m/s) } & \multicolumn{3}{c}{ Maré de Vazante (m/s) } \\
\cline { 2 - 7 } & $\begin{array}{c}\text { Mínima } \\
\text { média }\end{array}$ & $\begin{array}{c}\text { Máxima } \\
\text { média }\end{array}$ & Média & $\begin{array}{c}\text { Mínima } \\
\text { média }\end{array}$ & $\begin{array}{c}\text { Máxima } \\
\text { média }\end{array}$ & Média \\
\hline 1 & 0,17 & 0,39 & 0,26 & 0,27 & 0,53 & 0,40 \\
\hline 2 & 0,12 & 0,23 & 0,17 & 0,16 & 0,33 & 0,26 \\
\hline
\end{tabular}

Fonte: Costa Neto et al. (2003).

A precipitação pluviométrica observada no período de maio a setembro de 2004 em uma estação meteorológica instalada na sede administrativa da fazenda de cultivo de camarão da Camarus Aquacultura do Nordeste Ltda mostrou uma precipitação acumulada no período de 147,2 mm, onde os meses de junho e julho apresentaram os maiores volumes (Tabela II). 
Tabela II- Precipitação pluviométrica na área da fazenda de cultivo de camarão da Camarus Aquacultura do Nordeste para o período de maio a setembro de 2004.

\begin{tabular}{l|c|c|c|c|c}
\hline \multicolumn{1}{c|}{ MESES } & Maio & Junho & Julho & Agosto & $\begin{array}{c}\text { Setembr } \\
\text { o }\end{array}$ \\
\hline $\begin{array}{l}\text { Precipitação } \\
(\mathrm{mm})\end{array}$ & 8,4 & 83,4 & 36,6 & 1,8 & 17,0 \\
\hline Acumulado (mm) & \multicolumn{4}{|c}{147,2} \\
\hline
\end{tabular}

Fonte: Estação meteorológica instalada na Camarus Aquacultura do Nordeste Ltda.

\section{METODOLOGIA UTILIZADA}

A metodologia do presente trabalho pode ser dividida em quatro etapas, a saber: précampo, onde foi realizado o reconhecimento de campo; a etapa de campo, em que estão incluídos o monitoramento topográfico e a amostragem de água; a etapa de laboratório, na qual são executadas as análises de água; e por fim a etapa de gabinete, onde são processados os dados coletados nas etapas anteriores, as quais serão descritas a seguir.

Durante a fase de Pré-Campo foi realizado o reconhecimento de campo onde foram escolhidos 6 pontos ao longo dos CDs, sendo 4 no CD 1 e 2 no CD 2 (Figura 03), em locais que apresentavam evidencia de erosão. Os pontos foram locados na parte superior dos taludes e monumentados com marcos de concreto. Posteriormente, foram obtidas as coordenadas UTM de todos os marcos (Tabela III), utilizando o sistema de DGPS pelo método estático (modelo ProMarck 2 - Ashtech) a partir do RN de primeira ordem do IGBE $\mathrm{n}^{\circ}$ SB 241108 com cota de 28,8 m e coordenadas UTM 802804,917 m E e $9422032,083 \mathrm{~m}$ N. Foi utilizado o datum de referência WGS 84. Este método permite uma precisão horizontal de $0,005 \mathrm{~m}+1$ ppm e precisão vertical de $0,01 \mathrm{~m}+2 \mathrm{ppm}$.

A etapa de Campo consta do monitoramento topográfico, amostragem de água e caracterização textural dos sedimentos do fundo do canal. O monitoramento topográfico é realizado através de perfis perpendiculares aos CDs, numa periodicidade mensal e sempre durante a baixa-mar das marés de sizígia, momentos onde ocorrem as maiores amplitudes de marés, que expõem os canais e facilitam a visualização das feições de erosão e deposição. O referido levantamento é realizado com um Medidor Eletrônico de Distânica (MED), tipo estação total modelo Elta 50 (Trimble Zeiss) que opera emitindo feixes de microondas com comprimento $1<\lambda<10 \mathrm{~cm}$, que permite uma precisão linear de $5 \mathrm{~mm}+$ 3 ppm e uma precisão angular de 5 ',

A estação total é fixada no tripé e colocada sobre o marco de concreto, depois de devidamente nivelada é orientada no sentido do perfil, a partir de então, o prisma vai sendo posto em pontos onde seja observada alguma variação topográfica. Os perfis estão amarrados em pontos notáveis no terreno a partir do ângulo horizontal entre eles, de forma a permitir a mesma orientação da linha de visada ao longo do monitoramento. Mensalmente são coletadas a diferença de nível e a distância horizontal entre os pontos que apresentam variação topográfica ao longo dos perfis. 


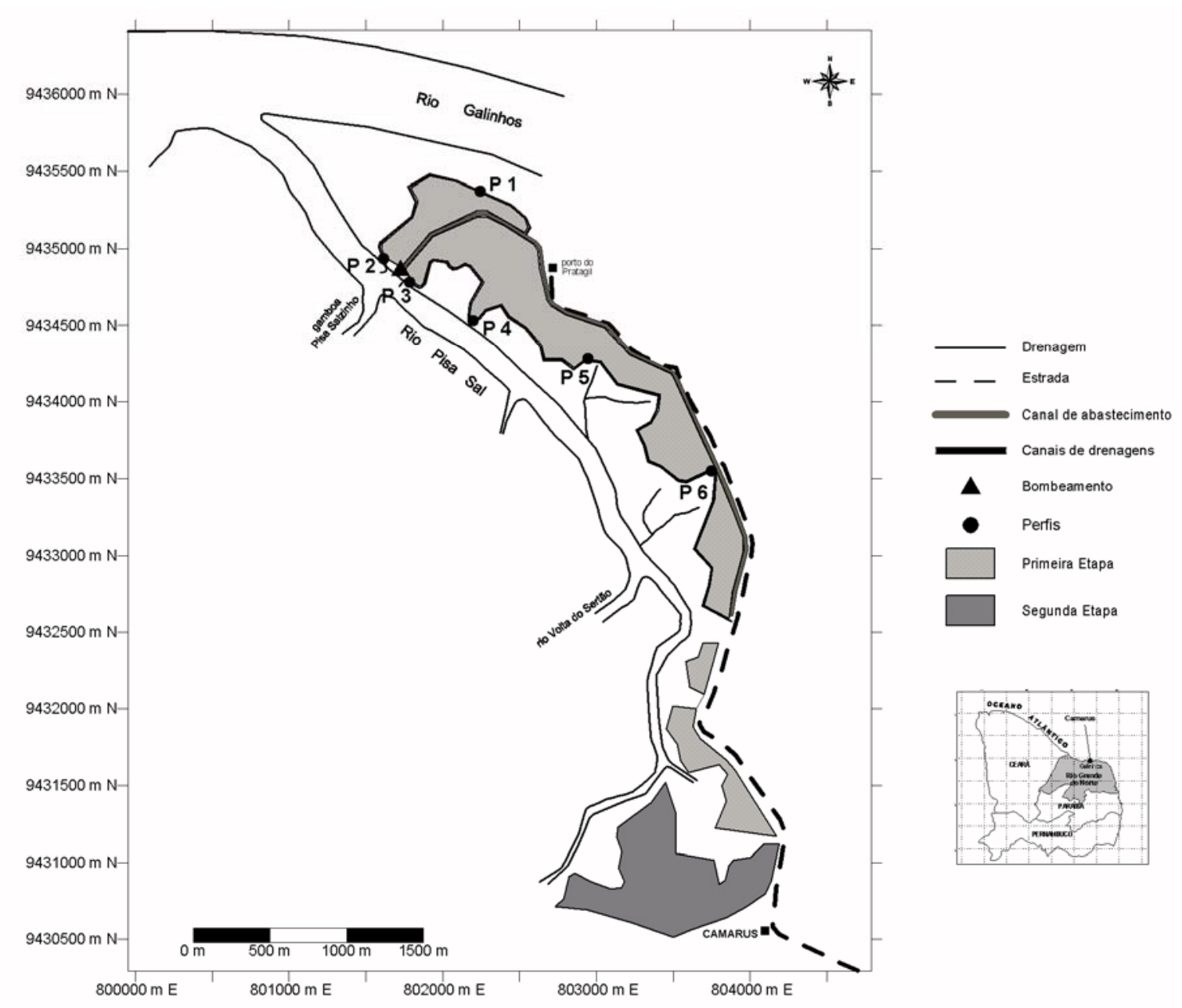

Figura 03- Mapa de localização dos perfis.

Tabela III- Coordenadas UTM e cotas dos marcos dos perfis.

\begin{tabular}{c|c|c|c}
\hline Perfis & $\begin{array}{c}\text { UTM E } \\
\text { (m) }\end{array}$ & $\begin{array}{c}\text { UTM N } \\
\text { (m) }\end{array}$ & $\begin{array}{c}\text { Cota } \\
\text { (m) }\end{array}$ \\
\hline P 1 & 802229,032 & 9435359,183 & 4,049 \\
\hline P 2 & 801628,075 & 9434960,490 & 3,840 \\
\hline P 3 & 801796,686 & 9434791,434 & 4,557 \\
\hline P 4 & 802203,964 & 9434534,521 & 4,005 \\
\hline P 5 & 802938,060 & 9434286,549 & 3,109 \\
\hline P 6 & 803742,462 & 9433556,017 & 3,320 \\
\hline
\end{tabular}

As amostragens de água são realizadas com garrafas PET previamente lavadas. No momento da coleta as garrafas são lavadas de 3 a 5 vezes com a água do próprio local da coleta, posteriormente são introduzidas na água e posicionadas a uma altura de aproximadamente 10 a $20 \mathrm{~cm}$ do fundo do canal, com a boca sempre orientada contra a corrente de maré. São coletados em média um volume 1,5 litros de água para realização de 
análises da concentração de sólidos suspensos (SS) utilizando espectrofotômetro. Essas análises só foram realizadas até o mês de julho, em virtude da quebra do espectofotômetro.

Também foram coletados aproximadamente $500 \mathrm{~g}$ de sedimentos do fundo dos canais e acondicionados em sacos plásticos. A caracterização textural dos sedimentos de fundo é realizada macroscopicamente utilizando a seguinte classificação: grânulo, areia (muito grossa, grossa, média, fina e muito fina), silte e argila. Posteriormente, as amostras passarão por separação granulométrica nas frações: 2,$0 ; 1,0 ; 0,5 ; 0,25 ; 0,125 ; 0,0625$ e < $0,0625 \mathrm{~mm}$ e classificadas estatisticamente.

Nos trabalhos de gabinete são realizados os processamentos dos dados coletados nas fazes de campo e laboratório, bem como a elaboração do mapa de localização dos perfis. Os do levantamento topográfico são tabulados no software Excel, elaborando-se gráficos de dispersão mensais de todos perfis. Da mesma forma, os resultados das análises de água também são levados ao Excel para confecção de gráficos de barras. Para confecção da base cartográfica foi utilizado o software ArcGis.

\section{RESULTADOS OBTIDOS}

Os perfis topográficos apresentados nas figuras 04 a 09 auxiliam a identificação dos processos de erosão e sedimentação ao longo dos CDs no período de junho a outubro de 2004, os quais não apresentam variação significativas ao longo dos 5 meses de monitoramento (Figuras 04 a 07).

Entretanto, pode-se observar que no CD 1, mais precisamente nos perfis 04 (Figura 05), 05 (Figura 06) e 06 (Figura 07) ocorreram pequenas áreas de erosão e deposição. Estes perfis mostram a ocorrência de áreas erodidas na sua margem esquerda iniciadas a partir do mês de junho e que estão evoluindo até o mês de outubro, as quais são corroboradas com observações in situ. O perfil 06 (Figura 07) apresenta sutis variações topográficas indicando sucessivas fases alternadas de erosão (julho-agosto e setembro-outubro) e sedimentação (agosto e setembro). Na margem direita do perfil 05 (Figura 06) ocorre sedimentação na porção compreendida entre as cotas de 1,5 a 0,5 m e no centro do canal. A morfologia dos perfis localizados no CD 2 (Figuras 08 e 09) não apresentou variações significativas ao longo do período estudado.

A tabela IV apresenta a caracterização semi-quantitativa dos processos de erosão e deposição no período de julho a outubro de 2004 ao longo dos canais de despesca (CD 1 e CD 2), mostrando que a ocorrência desses processos não foi significativa, predominando de uma forma geral, ausência destes fenômenos. Na margem esquerda do CD 1 é mais comum a ocorrência de erosão e o CD 2 está em equilíbrio morfológico. 


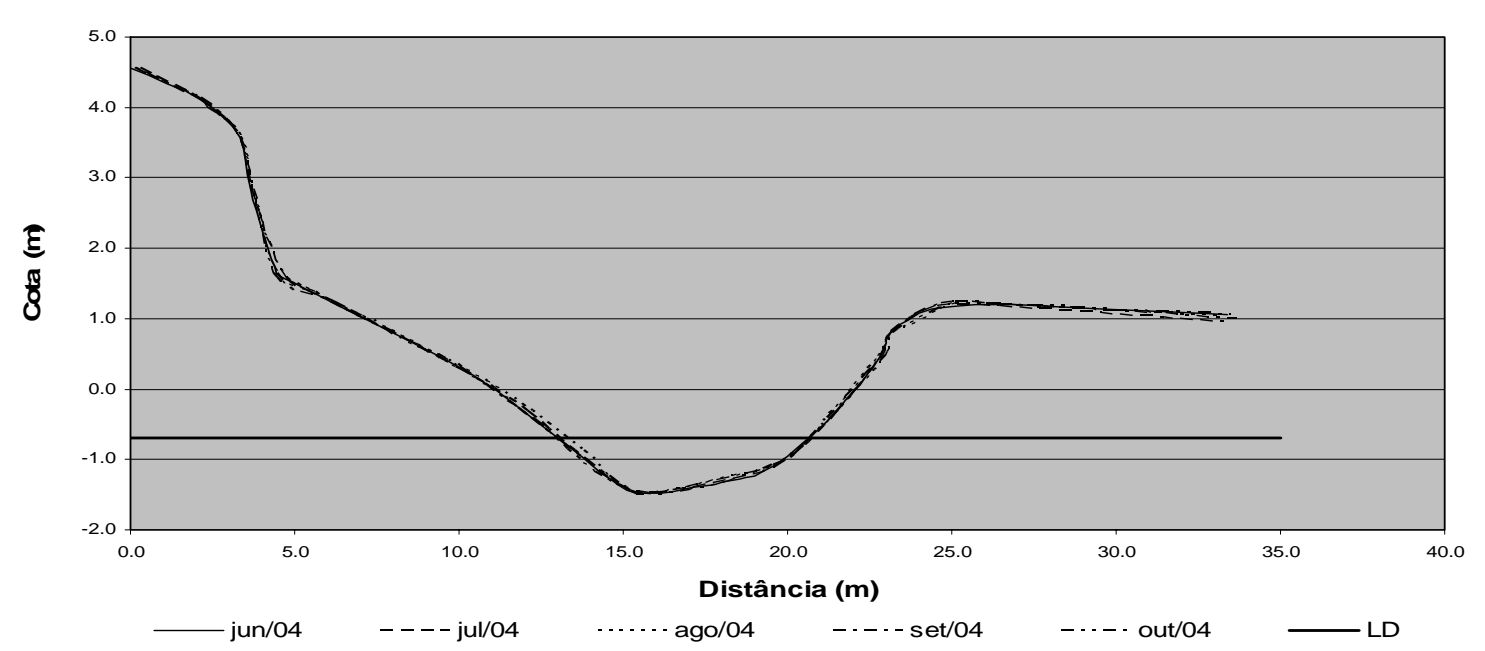

Figura 04- Perfil P 03 mostrando a variação topográfica no período de junho a outubro de 2004 (LD - linha d’água).

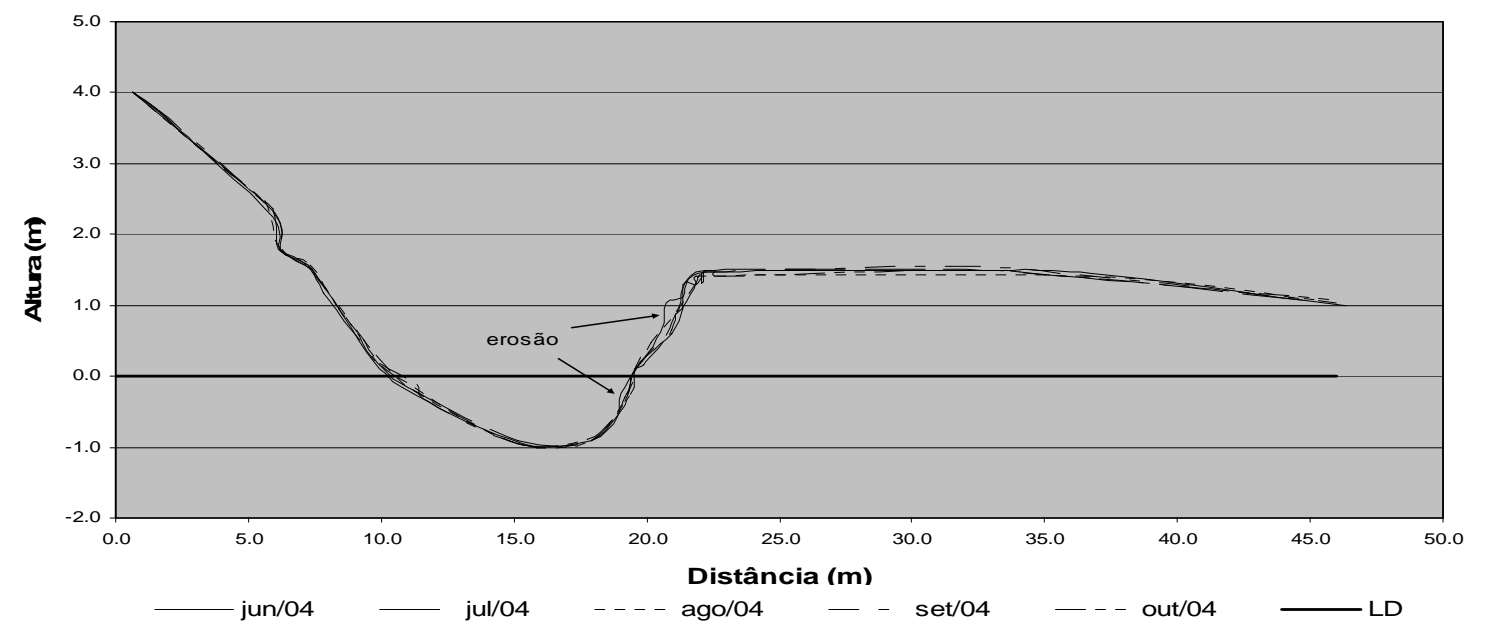

Figura 05- Perfil P 04 mostrando a variação topográfica no período de junho a outubro de 2004 (LD - linha d’água). 


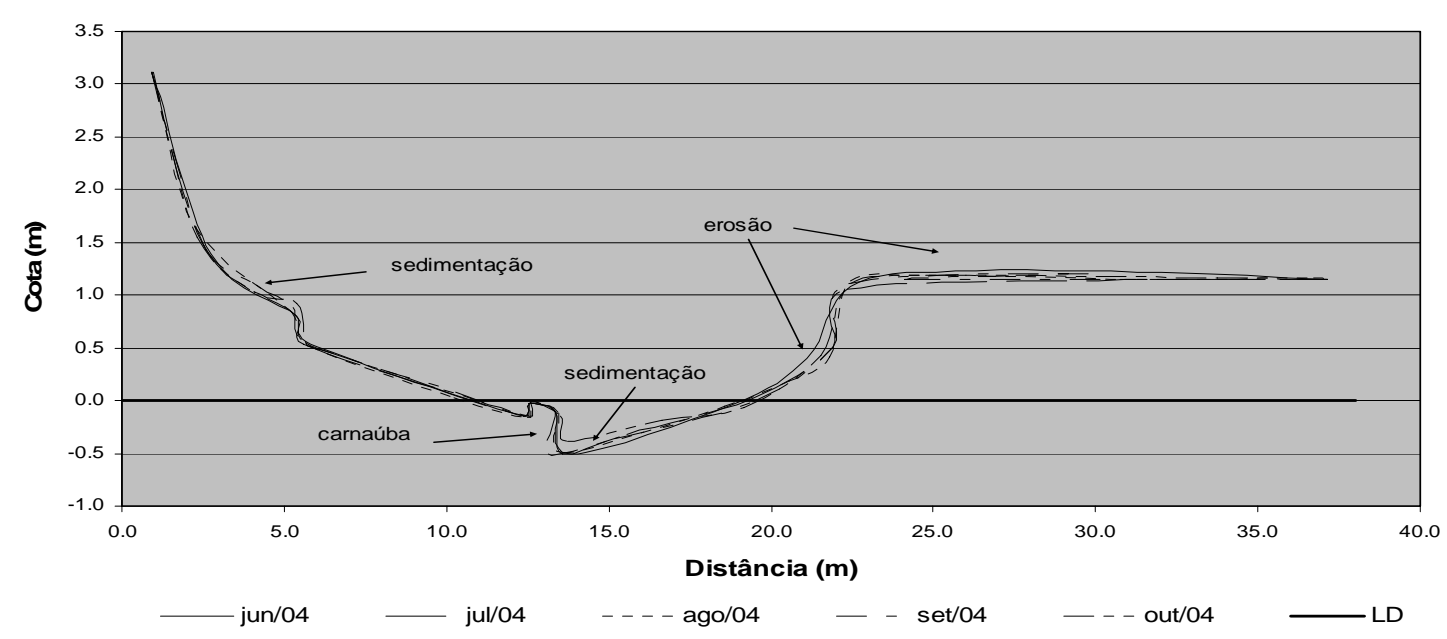

Figura 06- Perfil P 05 mostrando a variação topográfica no período de junho a outubro de 2004 (LD - linha d’água).

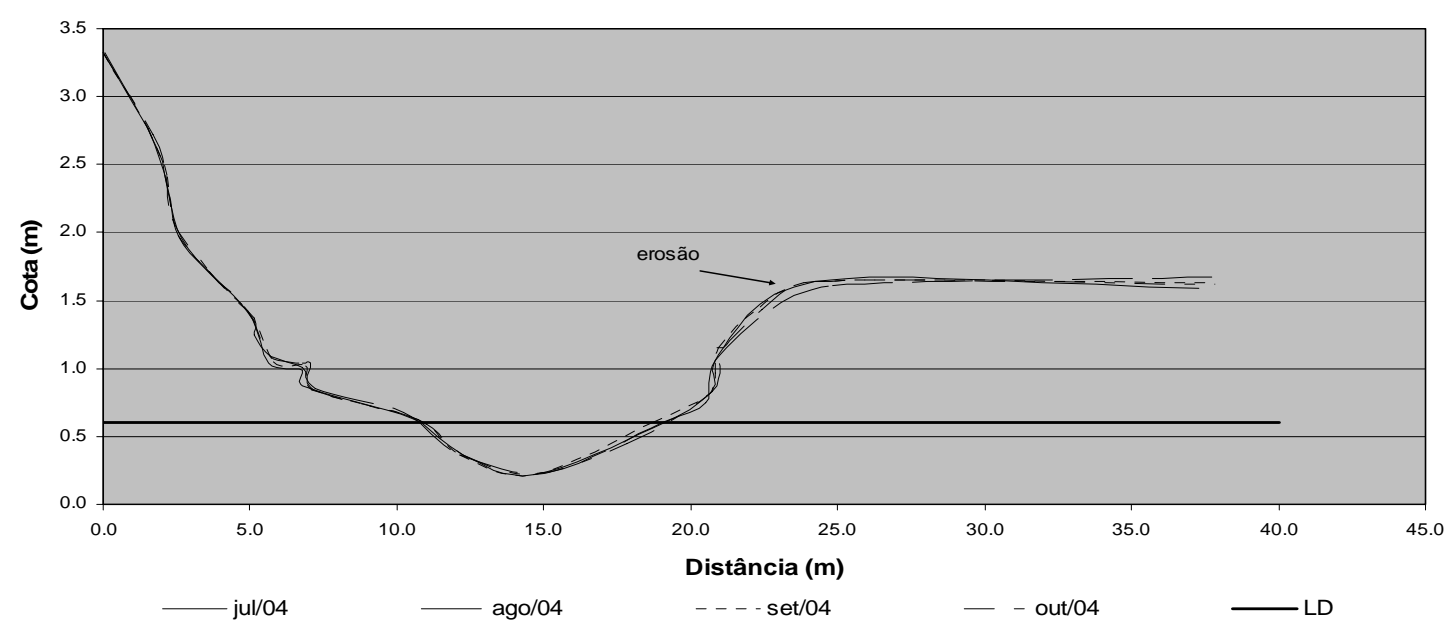

Figura 07- Perfil P 06 mostrando a variação topográfica no período de julho a outubro de 2004 (LD - linha d’água). 


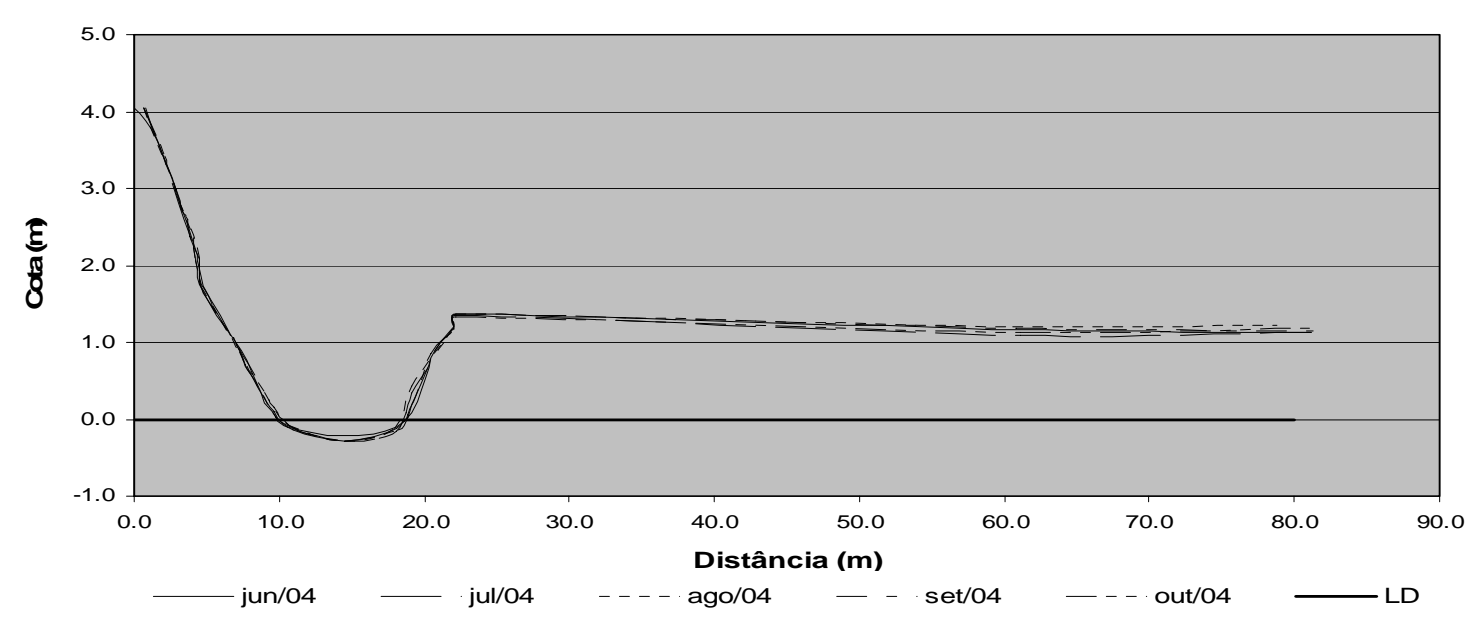

Figura 08- Perfil P 01 mostrando a variação topográfica no período de junho a outubro de 2004 (LD - linha d’água).

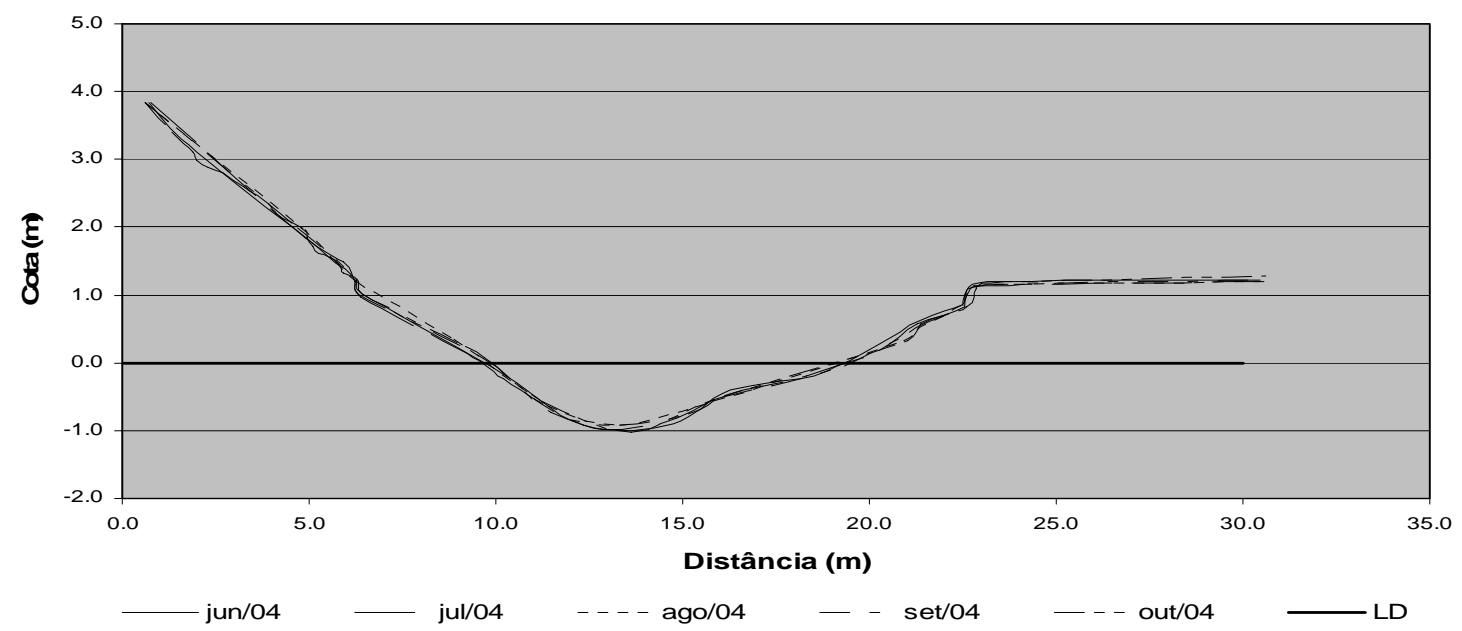

Figura 09- Perfil P 02 mostrando a variação topográfica no período de junho a outubro de 2004 (LD - linha d’água).

Tabela IV- Classificação semi quantitativa dos processos de erosão e deposição nos CDs durante o período estudado.

\begin{tabular}{|c|c|c|c|c|c|c|c|}
\hline \multirow{2}{*}{\multicolumn{2}{|c|}{ PERFIS }} & \multicolumn{2}{|c|}{$\begin{array}{c}\text { MARGEM } \\
\text { DIREITA }\end{array}$} & \multicolumn{2}{|c|}{ CENTRO } & \multicolumn{2}{|c|}{$\begin{array}{l}\text { MARGEM } \\
\text { ESQUERDA }\end{array}$} \\
\hline & & Erosão & Deposição & Erosão & Deposição & Erosão & Deposição \\
\hline P 01 & \multirow{2}{*}{ CD 2} & Aus & Aus & Aus & Aus & Aus & Aus \\
\hline P 02 & & Aus & Aus & Aus & Aus & Aus & Aus \\
\hline P 03 & \multirow{4}{*}{ CD 1} & Aus & Aus & Aus & Aus & Aus & Aus \\
\hline P 04 & & Aus & Aus & Aus & Aus & NSig & Aus \\
\hline P 05 & & Aus & NSig & Aus & NSig & NSig & Aus \\
\hline P 06 & & Aus & Aus & Aus & Aus & NSig & Aus \\
\hline
\end{tabular}

Significativa (Sig), Não significativa (NSig) e Ausente (Aus). 
Os resultados das análises dos sólidos suspensos mostram maior de concentração no mês de junho, principalmente nos perfis 05 e 06 (montante do CD 1), ocorrendo diminuição no mês subseqüente (Figura 10). Isto deve-se a penetração das marés associada a incidência acumulada de chuva nos meses de maio e junho, que atingiram 91,8 mm.

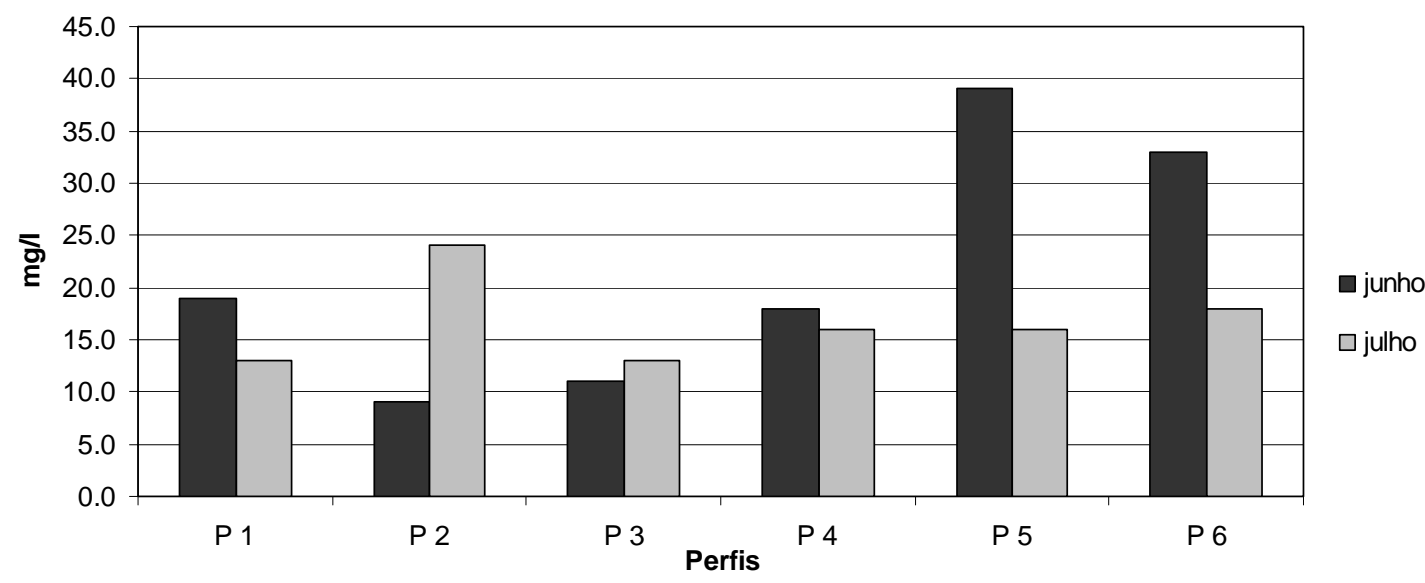

Figura 10- Sólidos suspensos nos meses de junho e julho/2004.

A análise textural dos sedimentos dos canais e das suas margens mostraram que predomina no centro do canal nos perfis mais próximos a sua desembocadura os sedimentos areia, cascalho e pouca lama, como mostram os perfis P 02, P 03 e P 04. Nos perfis localizados mais distantes da desembocadura (P 01, P 05 e P 06) predominam sedimentos lamosos. Nas margens dos canais ocorrem exclusivamente lamas arenosas (Tabela V).

Tabela V- Classificação textural dos sedimentos de fundo dos CDs.

\begin{tabular}{|c|c|c|c|c|}
\hline \multicolumn{2}{|c|}{ PERFIS } & $\begin{array}{l}\text { MARGEM } \\
\text { DIREITA }\end{array}$ & CENTRO & $\begin{array}{c}\text { MARGEM } \\
\text { ESQUERD } \\
\text { A }\end{array}$ \\
\hline P 01 & \multirow{2}{*}{ CD 1} & $\begin{array}{c}\text { Lama } \\
\text { arenosa }\end{array}$ & Lama & $\begin{array}{c}\text { Lama } \\
\text { arenosa }\end{array}$ \\
\hline P 02 & & $\begin{array}{c}\text { Lama } \\
\text { arenosa }\end{array}$ & Areia & $\begin{array}{c}\text { Lama } \\
\text { arenosa }\end{array}$ \\
\hline P 03 & \multirow{4}{*}{ CD 2} & $\begin{array}{c}\text { Lama } \\
\text { arenosa }\end{array}$ & Cascalho arenoso & $\begin{array}{c}\text { Lama } \\
\text { arenosa }\end{array}$ \\
\hline P 04 & & $\begin{array}{c}\text { Lama } \\
\text { arenosa }\end{array}$ & $\begin{array}{c}\text { Lama, areia e } \\
\text { cascalho }\end{array}$ & $\begin{array}{c}\text { Lama } \\
\text { arenosa }\end{array}$ \\
\hline P 05 & & $\begin{array}{c}\text { Lama } \\
\text { arenosa }\end{array}$ & Lama & $\begin{array}{c}\text { Lama } \\
\text { arenosa }\end{array}$ \\
\hline P 06 & & $\begin{array}{c}\text { Lama } \\
\text { arenosa }\end{array}$ & Lama & $\begin{array}{c}\text { Lama } \\
\text { arenosa }\end{array}$ \\
\hline
\end{tabular}




\section{CONSIDERAÇÕES FINAIS}

Com base nas análises feitas através da observação dos perfis topográficos, realizados no período de junho a outubro de 2004, conclui-se que os processos de erosão e sedimentação atuantes no interior dos CDs não são significativos numa escala temporal de pequena amplitude, seja mensal, bimestral ou semestral. A erosão/sedimentação é decorrente das correntes de marés no interior dos canais, principalmente as relacionadas ao período de maré vazante. Fatores como a atividade de despesca também interfere no desenvolvimento destes processos, bem como a ação das chuvas erodindo os taludes dos viveiros. Posteriormente, os volumes de sedimentos erodidos e depositados serão quantificados em cada perfil utilizando o software Surfer.

O CD 1 apresenta configuração morfológica em equilíbrio, provavelmente devido aos seguintes fatores: pequena extensão, configuração geométrica com pouca variação em direção a montante, baixa velocidade das correntes de marés e presença de apenas uma comporta de despesca.

O CD 2 apresenta trechos onde ocorrem processos não significativos de erosão/deposição, como observado nos perfis P 04 a P 06 (Figuras 05 a 07). A erosão ocorre, predominantemente, na margem esquerda dos canais, enquanto a sedimentação ocorre na margem direita e no centro do perfil P 05 (Figura 06). A deposição no centro do canal é induzida pela presença de troncos de carnaúbas que eram utilizados como obras rígidas para contenção da erosão. O P 03 (Figura 04) não mostra evidência de modificação morfológica ao longo do período estudado, mesmo sendo observado nas sua foz intensos processos erosionais. Estes processos são decorrentes dos seguintes fatores: grande extensão, configuração irregular, curvas com fortes ângulos, alta velocidade das correntes de marés e grande número de comportas de despesca.

O transporte de sedimentos suspensos está associado as correntes de marés no interior dos canais e as chuvas que caem na região. As maiores concentrações de sedimentos suspensos a montante dos CDs deve-se a diminuição das correntes de marés que não conseguem transportá-los com eficiência. Nas áreas próximas as desembocaduras dos CDs a concentração de SS é menor, uma vez que as fortes das correntes de marés provocam diluição de suas concentrações.

A predominância de sedimentos areia e cascalho nas proximidades das desembocaduras dos CDs deve-se as fortes correntes de fundo que transportam os sedimentos finos em direção ao rio Pisa Sal. A montante dos CDs predominam sedimentos lamosos depositados pelas fracas correntes. Nas margens dos CDs predominam lamas arenosas depositadas em função da baixa energia desse ambiente.

O projeto de estudo de quantificação da variação morfo-sedimentar dos CDs terá duração de 2 anos, se estendendo até maio de 2006, onde ainda serão desenvolvidos medições das direções e velocidades das correntes de marés no interior dos canais, bem como a separação granulométrica e classificação textural dos sedimentos. 


\section{REFÊNCIAS BIBLIOGRÁFICAS}

Camarus Aquacultura do Nordeste Ltda. Estudo de Impacto Ambiental (EIA-RIMA) Diagnóstico Ambiental. Natal-RN, v. 2, p. 40-313, 2003.

Costa Neto, L.X., Rocha, A.M.R., Pena, O.M.L., Lima, J.C.F., Lopes, L.A.A., Medeiros, M.B.B. e Cabral, A.P. Geologia da área de intervenção de uma fazenda de criação de camarão no município de Galinhos-RN. Anais do XLII Congresso Brasileiro de Geologia, Araxá-MG, CD ROOM, S17: 667, 2004.

Costa Neto, L.X., Rocha, A.M.R., Pena, O.M.L., Lima, J.C.F., Lopes, L.A.A., Medeiros, M.B.B. e Cabral, A.P. Correntes de marés no estuário do rio Pisa Sal, Galinhos-RN: Uma primeira aproximação. Anais do XX Simpósio de Geologia do Nordeste, Fortaleza-CE, p. 517-518, 2003. 